Article

\title{
An Association Rule Mining Analysis of Lifestyle Behavioral Risk Factors in Cancer Survivors with High Cardiovascular Disease Risk
}

\author{
Su Jung Lee ${ }^{1}\left(\mathbb{D}\right.$ and Kathleen B. Cartmell ${ }^{2, *}$ \\ 1 Research Institute on Nursing Science, School of Nursing, Hallym University, 1 Hallymdaehak-gil, \\ Chuncheon-si 24252, Korea; sujunglee@hallym.ac.kr \\ 2 Department of Public Health Sciences, Clemson University, 519 Edwards Hall, Alpha Epsilon Drive, \\ Clemson, SC 29634, USA \\ * Correspondence: kcartme@clemson.edu; Tel.: +1-864-656-2719; Fax: +1-864-656-6227
}

check for

updates

Citation: Lee, S.J.; Cartmell, K.B. An Association Rule Mining Analysis of Lifestyle Behavioral Risk Factors in Cancer Survivors with High Cardiovascular Disease Risk. J. Pers. Med. 2021, 11, 366. https://doi.org/ 10.3390/jpm11050366

Received: 29 March 2021

Accepted: 29 April 2021

Published: 2 May 2021

Publisher's Note: MDPI stays neutral with regard to jurisdictional claims in published maps and institutional affiliations.

Copyright: (c) 2021 by the authors. Licensee MDPI, Basel, Switzerland. This article is an open access article distributed under the terms and conditions of the Creative Commons Attribution (CC BY) license (https:/ / creativecommons.org/licenses/by/ $4.0 /)$.

\begin{abstract}
We aimed to assess which lifestyle risk behaviors have the greatest influence on the risk of cardiovascular disease in cancer survivors and which of these behaviors are most prominently clustered in cancer survivors, using logistic regression and association rule mining (ARM). We analyzed a consecutive series of 897 cancer survivors from the Korean National Health and Nutritional Exam Survey (2012-2016). Cardiovascular disease risks were assessed using the atherosclerotic cardiovascular disease score (ASCVDs). We classified participants as being in a low-risk group if their calculated ASCVDs was less than $10 \%$ and as being in a high-risk group if their score was $10 \%$ or higher. We used association rule mining to analyze patterns of lifestyle risk behaviors by ASCVDs risk group, based upon public health recommendations described in the Alameda 7 health behaviors (current smoking, heavy drinking, physical inactivity, obesity, breakfast skipping, frequent snacking, and suboptimal sleep duration). Forty-two percent of cancer survivors had a high ASCVD. Current smoking (common odds ratio, 11.19; 95\% confidence interval, 3.66-34.20, $p<0.001$ ) and obesity (common odds ratio, 2.67; 95\% confidence interval, 1.40-5.08, $p<0.001$ ) were significant predictors of high ASCVD in cancer survivors within a multivariate model. In ARM analysis, current smoking and obesity were identified as important lifestyle risk behaviors in cancer survivors. In addition, various lifestyle risk behaviors co-occurred with smoking in male cancer survivors.
\end{abstract}

Keywords: cancer survivor; lifestyle risk behavior; cardiovascular disease; health risk assessment; association rule mining

\section{Introduction}

The number of cancer survivors is rapidly increasing worldwide due to improvements in early diagnosis and treatment of cancer [1]. Due to these advances in cancer diagnosis and treatment, deaths due to treatment complications and other chronic diseases are gradually increasing in cancer patients [2]. Several recent studies have reported that cancer survivors have a high risk of cardiovascular disease [3], and cancer survivors who are at risk of cardiovascular disease have a significantly higher mortality rate than those who do not have cardiovascular risk [4,5]. In particular, this disease trend is prominent among cancer survivors who have survived for over five years [6,7], and the risk of cardiovascular disease in long-term cancer survivors is actually higher than the recurrence rate of cancer [8].

There are several causes of increased cardiovascular risk in cancer survivors. First, cardiotoxic drug treatments such as anthracycline [9], paclitaxel, and trastuzumab [10], and mediastinal radiation therapy can directly damage the cardiovascular system [11]. Second, cancer is usually associated with thrombosis due to pro-inflammatory cytokines and endothelial damage, which in turn increases the risk of cardiovascular disease in cancer survivors [12]. Third, risk factors related to lifestyle, such as obesity and low physical 
activity, which are common among cancer survivors can increase the risk of cardiovascular disease in cancer survivors [13]. According to a Canadian Lerond report, factors that contribute to health and the development of chronic diseases are $20 \%$ attributable to genetic factors, $20 \%$ to environmental factors, $8 \%$ to medical services, and $52 \%$ to personal lifestyle factors [14]. In other words, lifestyle risks such as physical inactivity, smoking, and alcohol consumption are the main factors that contribute to chronic disease risk [15]. In particular, ischemic heart disease is mainly attributable to lifestyle risk behaviors such as lack of exercise, excessive drinking, smoking, and obesity [16]. However, most previous studies have focused on individual lifestyle risk behaviors in cancer survivors. In other words, most of the studies analyzed only selective lifestyle factors such as smoking and obesity, or only analyzed data using the simple sum of the number of lifestyle risk factors $[17,18]$. It is difficult to identify specific lifestyle factors that are related to each other, or that cluster together in individuals. Thus, we aimed to assess which lifestyle risk factors influence the risk of cardiovascular disease in cancer survivors and which of these factors tend to cluster together in cancer survivors using logistic regression and association rule mining (ARM).

\section{Materials and Methods}

\subsection{Study Design and Participants}

This study was conducted as a cross-sectional analysis of the fifth period (2012), the sixth period (2013-2015) and the seventh period (2016) of the Korea National Health and Nutrition Examination Survey. We conducted this research after approval of exemption from review by the Institutional Board and Ethics Committee (IRB number: HIRB-2020022). KNHANES participants are a representative population whose records are extracted randomly by resident registration number and housing census numbers in South Korea. The components of this study consist of a health survey, a medical examination, and a nutritional survey, which are conducted by trained research staff. The health survey is conducted through personal interviews, and the examination is conducted by direct measurement. Among a total of 39,156 participants in the 2012-2016 KNHANES Survey, 1017 respondents answered yes to the question, "Have you ever been diagnosed with cancer by a doctor?". Of these, 897 were the final subjects for this analysis, with exclusion of 120 patients who had missing clinical data.

\subsection{Measures}

\subsubsection{Demographic and Disease Characteristics}

We included age, gender, household income level, degree of education, and marital status of the subjects. Household income was defined as total income in the family divided by the total number within a family and divided into four quartiles (lower, lower middle, upper middle, upper). Level of education was classified as less than 6 years, 7-9 years, $10-12$ years, and 13 years or more. Marital status was classified as 'living with a spouse or domestic partners' or as 'single, divorced or widowed'.

\subsubsection{Anthropometric Characteristics}

Among the examination items, this study used height, weight and blood pressure, which were measured by a trained examiner. Blood pressure was measured three times in a sitting position by a trained examiner, with five-minute breaks between measurements, and the average of the three measurements was used for the blood pressure parameter. For blood tests, subjects were asked to fast for a minimum of $8 \mathrm{~h}$ before taking the test. Blood tests were collected, following overnight fasting of at least eight hours. Blood cholesterol and glucose status were measured by Hitachi automatic analyzer 7600 (Tokyo, Japan).

\subsubsection{Lifestyle Risk Behaviors}

Lifestyle risk behaviors were identified based upon the Alameda County studies, which reported that individual health behaviors are highly linked to disease occurrence and death [19]. Therefore, we included current smoking, heavy drinking, physical inactivity, 
obesity, breakfast skipping, frequent snacking, and sub-optimal sleep duration as lifestyle risk behaviors. Smoking was defined as having smoked more than 100 cigarettes in one's lifetime or being a current smoker [20]. Heavy drinking was defined for men as drinking 7 or more cups and for women as drinking 5 or more cups at a time at least twice a week [21]. Physical inactivity was defined as the lack of participation in either high intensity exercise (for more than $25 \mathrm{~min}$ once a week for more than three days) or moderate intensity exercise (for more than $30 \mathrm{~min}$ five times a week) [22]. Breakfast skipping was defined as not eating breakfast either that day or the day before. Frequent snacking was defined as eating between meals 3 or more times per day, whereas infrequent snacking was defined as snacking fewer than 3 times per day, regardless of type and quantity [23]. Sub-optimal sleep was defined as sleeping either less than 7 or more than $8 \mathrm{~h}$ per night [24].

\subsubsection{Cardiovascular Risk}

To assess cardiovascular disease risk, we used the atherosclerotic cardiovascular disease (ASCVD) risk score, as revised in 2013 [25]. The ASCVD is a simple method for calculating the risk of being diagnosed with cardiovascular disease within ten years, calculated based upon age, total cholesterol, high-density lipoprotein cholesterol, hypertension, diabetes, systolic blood pressure, and smoking status. We classified participants as being in the low-risk group if their calculated ASCVDs was less than $10 \%$ and as being in the high-risk group if their ASCVDs was 10\% or higher.

\subsubsection{Statistical Analysis}

We compared demographic and clinical characteristics between the low and high ASCVD groups using the $\chi 2$ or t-test (or Mann-Whitney $U$ test). We performed binary logistic regression analysis to assess which lifestyle risk behaviors were related to high ASCVD score. The association between lifestyle risk behaviors and high ASCVD were analyzed after adjustment for statistically significant demographic variables, and their association was reported as an odds ratio (OR) with $95 \%$ confidence interval (CI). Variables with $p$ value less than 0.05 in the univariate model were included in the multivariate model as an 'input' method.

\subsubsection{Association Rule Mining}

The ARM was first introduced by Agrawal et al. as an analysis method that quantifies the simultaneous correlations between various features in a cluster [26]. In other words, dichotomous variables are often found together within a group of interest, and among them, highly correlated variables with respect to a particular target are found with statistical parameters [27]. The a priori algorithm is the most well-known ARM algorithm and quantifies the correlation of the most frequent occurrences of items with high support, confidence, and lift, showing that each occur frequently within a given group [28]. The support for the rule $(\mathrm{A} \rightarrow \mathrm{B})$ is the probability that the two behaviors occur together.

$$
\text { Support }(\mathrm{A} \rightarrow \mathrm{B})=P(\mathrm{~A} \cap \mathrm{B})=\frac{\text { Number of persons having } A \text { and } B}{\text { Total number of persons }}
$$

The confidence for the rule $(\mathrm{A} \rightarrow \mathrm{B})$ is the conditional probability of having $\mathrm{B}$ given that a patient has an $\mathrm{A}$ item.

The lift of the rule $(\mathrm{A} \rightarrow \mathrm{B})$ is the confidence of the rule divided by the unconditional probability of the consequent (B).

$$
\text { Lift }(\mathrm{A} \rightarrow \mathrm{B})=\frac{\text { Confidence }(A \rightarrow \mathrm{B})}{\text { Support }(B)}
$$

The higher the lift value between two variables, the higher the correlation of the two variables. The left-hand side of the rule (e.g., A) is the antecedent and the right-hand side the consequent (e.g., B) 
We present the statistical significance of the association rules using the chi-square test. All statistical methods were performed with $\mathrm{R}$ version 3.6.3 (the R foundation)

\section{Results}

A total of 897 cancer survivors were included in the final analysis. Of the 897 subjects, $358(39.9 \%)$ were males and $539(60.1 \%)$ were females. The mean age of subjects was $62.2( \pm 8.1)$ years, respectively. A large proportion of cancer survivors reported physical inactivity, breakfast skipping, obesity, heavy drinking, and current smoking. Breakfast skipping and frequent snacking were more frequent in low-risk groups than in high-risk groups. Current smoking was found to be twice as prevalent in the high-risk group, as compared to the low-risk group.

\subsection{Predictors of Lifestyle Risk Behaviors That Are Associated with High ASCVD Risk}

Table 1 displays the comparison of baseline characteristics and health risk behaviors between low and high ASCVD score groups. In crude comparison of demographic and laboratory parameters, age, male gender, low educational year, marital status, diabetes and cardiometabolic laboratory parameters including, blood glucose, blood pressure, and cholesterol levels were associated with high ASCVD risk.

Table 1. Comparison of baseline characteristics between low and high ASCVD score in cancer survivors.

\begin{tabular}{|c|c|c|c|c|}
\hline & \multicolumn{3}{|c|}{ ASCVD Score } & \multirow[t]{2}{*}{$p$ Value } \\
\hline & Low $(N=520)$ & High $(\mathbf{N}=377)$ & Total $(\mathrm{N}=897)$ & \\
\hline Age & $54.8 \pm 9.6$ & $72.3 \pm 5.6$ & $62.2 \pm 8.1$ & $<0.001$ \\
\hline Male & $113(21.7 \%)$ & $245(65.0 \%)$ & $358(39.9 \%)$ & $<0.001$ \\
\hline BMI, $\mathrm{kg} / \mathrm{m}^{2}$ & $23.6 \pm 3.2$ & $23.8 \pm 3.0$ & $23.7 \pm 3.1$ & 0.267 \\
\hline Household income & & & & 0.368 \\
\hline Lowest & $112(21.5 \%)$ & $98(26.0 \%)$ & $210(23.4 \%)$ & \\
\hline Lower middle & $129(24.8 \%)$ & $94(24.9 \%)$ & $223(24.9 \%)$ & \\
\hline Upper middle & $138(26.5 \%)$ & $85(22.5 \%)$ & $223(24.9 \%)$ & \\
\hline Highest & $141(27.2 \%)$ & $100(26.5 \%)$ & $241(27.0 \%)$ & \\
\hline Educational year & & & & $<0.001$ \\
\hline$\leq 6$ years & $127(24.4 \%)$ & $197(52.3 \%)$ & $324(36.1 \%)$ & \\
\hline 7-9 years & $87(16.7 \%)$ & $48(12.7 \%)$ & $135(15.1 \%)$ & \\
\hline $10-12$ years & $169(32.5 \%)$ & $68(18.0 \%)$ & $237(26.4 \%)$ & \\
\hline$\geq 13$ years & $137(26.4 \%)$ & $64(17.0 \%)$ & $201(22.4 \%)$ & \\
\hline Marital status & & & & $<0.001$ \\
\hline Yes & $426(81.9 \%)$ & $271(71.9 \%)$ & $697(77.7 \%)$ & \\
\hline No & $94(18.1 \%)$ & $106(28.1 \%)$ & $200(22.3 \%)$ & \\
\hline Hypertension & $31(6.0 \%)$ & $32(8.5 \%)$ & $63(7.0 \%)$ & 0.184 \\
\hline Diabetes & $4(0.8 \%)$ & $21(5.6 \%)$ & $25(2.8 \%)$ & $<0.001$ \\
\hline \multicolumn{5}{|l|}{ Dyslipidemia } \\
\hline Total cholesterol (mg/dL) & $190.5 \pm 36.6$ & $182.3 \pm 33.7$ & $187 \pm 35.6$ & 0.001 \\
\hline HDL cholesterol (mg/dL) & $52.0 \pm 12.5$ & $46.7 \pm 11.8$ & $49.8 \pm 12.5$ & $<0.001$ \\
\hline LDL cholesterol (mg/dL) & $113.8 \pm 33.2$ & $108.3 \pm 31.1$ & $111.5 \pm 32.5$ & 0.012 \\
\hline \multicolumn{5}{|l|}{ Blood pressure } \\
\hline Systolic (mmHg) & $115.8 \pm 14.9$ & $129.7 \pm 16.5$ & $121.6 \pm 17.0$ & $<0.001$ \\
\hline Diastolic $(\mathrm{mmHg})$ & $74.9 \pm 9.3$ & $72.7 \pm 9.7$ & $74.0 \pm 9.5$ & $<0.001$ \\
\hline Fasting blood glucose (mg/dL) & $100.6 \pm 25.1$ & $107.4 \pm 26.6$ & $103.5 \pm 25.9$ & $<0.001$ \\
\hline \multicolumn{5}{|l|}{ Alameda's heath risk behavior } \\
\hline Current smoking & $31(6.0 \%)$ & $55(14.6 \%)$ & $86(9.6 \%)$ & $<0.001$ \\
\hline Heavy drinking & $54(10.4 \%)$ & $54(14.3 \%)$ & $108(12.0 \%)$ & 0.092 \\
\hline Physical inactivity & $474(91.2 \%)$ & $361(95.8 \%)$ & $835(93.1 \%)$ & 0.011 \\
\hline Obesity & $146(28.1 \%)$ & $118(31.3 \%)$ & $264(29.4 \%)$ & 0.331 \\
\hline Suboptimal sleep & $68(13.1 \%)$ & $64(17.0 \%)$ & $132(14.7 \%)$ & 0.126 \\
\hline Breakfast skipping & $142(27.3 \%)$ & $87(23.1 \%)$ & $229(25.5 \%)$ & 0.175 \\
\hline Frequent snacking & $53(10.2 \%)$ & $5(1.3 \%)$ & $58(6.5 \%)$ & $<0.001$ \\
\hline
\end{tabular}

BMI, body mass index; HDL, high-density lipoprotein; LDL, low-density lipoprotein. 
Table 2 summarizes the logistic regression analysis of lifestyle risk behaviors in predicting high ASCVD risks in cancer survivors. In univariate models, current smoking and physical inactivity were predictors and frequent snacking was a negative predictor of high ASCVD risk. However, current smoking and obesity were significant predictors for high ASCVD in cancer survivors in the multivariate model. Physical inactivity was a positive predictor in the crude model. However, its association with the ASCVD risk was reversed in the fully adjusted model.

Table 2. Results of binary logistic regression analysis for predictors of high ASCVD score in cancer survivors.

\begin{tabular}{ccccc}
\hline & Crude Model & Model 1 & Model 2 & Model 3 \\
\cline { 2 - 5 } & \multicolumn{4}{c}{ OR (95\% CI) } \\
\hline Current smoking & $2.90(1.77-4.75)$ & 11.79 & 11.85 & 11.19 \\
Heavy drinking & $1.14(0.75-1.75)$ & $2.84(1.02-7.88)$ & $2.85(1.02-7.92)$ & $2.79(0.99-7.85)$ \\
Physical inactivity & $1.94(1.02-3.71)$ & $0.26(0.07-0.94)$ & $0.26(0.07-0.97)$ & $0.23(0.06-0.86)$ \\
Obesity & $1.12(0.83-1.52)$ & $2.81(1.49-5.32)$ & $2.84(1.50-5.38)$ & $2.67(1.40-5.08)$ \\
Suboptimal sleep & $1.44(0.98-2.13)$ & $2.02(0.87-4.70)$ & $2.06(0.88-4.82)$ & $1.90(0.79-4.57)$ \\
Breakfast skipping & $0.94(0.66-1.33)$ & $1.14(0.56-2.30)$ & $1.15(0.57-2.32)$ & $1.12(0.55-2.27)$ \\
Frequent snacking & $0.11(0.04-0.27)$ & $0.57(0.13-2.56)$ & $0.59(0.13-2.67)$ & $0.54(0.12-2.45)$ \\
\hline
\end{tabular}

Model 1: crude model with adjusting for age and sex. Model 2: model 1 with adjusting for educational year Model 3: model 2 with adjusting for household income and marital status.

\subsection{Result of Association Rule Mining}

Table 3 displays the result of significant association rules for high ASCVD risk in male cancer survivors. Men with physical inactivity, optimal sleep duration, and frequent snacking was the most frequent rule (rule No.2; count, 16), and it was associated with low ASCVD risk. Among important association rules, high ASCVD risk was associated with 4 important rules in male survivors, in which all the rules were associated with current smoking. Figure 1 depicts these associations with size and color quantitatively. However, in female survivors, there were no important rules associated with high ASCVD (Table 4, Figure 2) in ARM analysis. In particular, rules of frequent snacking in female survivors (rule No 1-4) had the highest lift value in ARM analysis.

Table 3. Results of a priori algorithms of for ASCVD score in male cancer survivors.

\begin{tabular}{|c|c|c|c|c|c|c|}
\hline & LHS & RHS & Support & Confidence & Lift & Count \\
\hline 1 & $\{S S=$ No, FS $=$ Yes $\}$ & $\{$ ASCVD_high $=$ Low $\}$ & 0.052 & 1.000 & 1.324 & 28 \\
\hline 2 & $\{\mathrm{PI}=$ Yes, FS = Yes $\}$ & $\{$ ASCVD_high $=$ Low $\}$ & 0.054 & 1.000 & 1.324 & 29 \\
\hline 3 & $\{\mathrm{HD}=\mathrm{No}, \mathrm{FS}=\mathrm{Yes}\}$ & $\{$ ASCVD_high $=$ Low $\}$ & 0.061 & 1.000 & 1.324 & 33 \\
\hline 4 & $\{\mathrm{CS}=\mathrm{No}, \mathrm{FS}=\mathrm{Yes}\}$ & $\{$ ASCVD_high $=$ Low $\}$ & 0.058 & 1.000 & 1.324 & 31 \\
\hline 5 & $\{C S=$ No, PI $=$ No $\}$ & $\{$ ASCVD_high $=$ Low $\}$ & 0.069 & 0.902 & 1.195 & 37 \\
\hline 6 & $\{\mathrm{HD}=\mathrm{No}, \mathrm{PI}=\mathrm{No}, \mathrm{IA}=\mathrm{No}\}$ & $\{$ ASCVD_high $=$ Low $\}$ & 0.067 & 0.900 & 1.192 & 36 \\
\hline 7 & $\{C S=\mathrm{No}, \mathrm{PI}=\mathrm{No}, \mathrm{IA}=\mathrm{No}\}$ & $\{$ ASCVD_high $=$ Low $\}$ & 0.067 & 0.900 & 1.192 & 36 \\
\hline 8 & $\{\mathrm{CS}=\mathrm{No}, \mathrm{PI}=\mathrm{No}, \mathrm{FS}=\mathrm{No}\}$ & $\{$ ASCVD_high $=$ Low $\}$ & 0.061 & 0.892 & 1.181 & 33 \\
\hline 9 & $\{C S=$ No, HD $=$ No, PI $=$ No, IA $=$ No, FS $=$ No $\}$ & $\{$ ASCVD_high $=$ Low $\}$ & 0.061 & 0.892 & 1.181 & 33 \\
\hline 10 & $\{\mathrm{PI}=\mathrm{No}, \mathrm{IA}=\mathrm{No}, \mathrm{BS}=$ Yes, $\mathrm{FS}=\mathrm{No}\}$ & $\{$ ASCVD_high $=$ Low $\}$ & 0.058 & 0.886 & 1.173 & 31 \\
\hline 11 & $\{\mathrm{HD}=\mathrm{No}, \mathrm{OB}=\mathrm{No}, \mathrm{BS}=\mathrm{Yes}\}$ & $\{$ ASCVD_high $=$ Low $\}$ & 0.135 & 0.820 & 1.086 & 73 \\
\hline 12 & $\{C S=N o, O B=$ No $, I A=N o, B S=N o\}$ & $\{$ ASCVD_high $=$ Low $\}$ & 0.332 & 0.803 & 1.063 & 179 \\
\hline
\end{tabular}

Abbreviation: LHS = left hand side, RHS = right hand side, $\mathrm{CS}=$ current smoking, $\mathrm{HD}=$ heavy drinking, $\mathrm{PI}=$ physical inactivity, $\mathrm{OB}=$ obesity, FS = frequent snacking, SS = Suboptimal sleep, BS = breakfast skipping. 


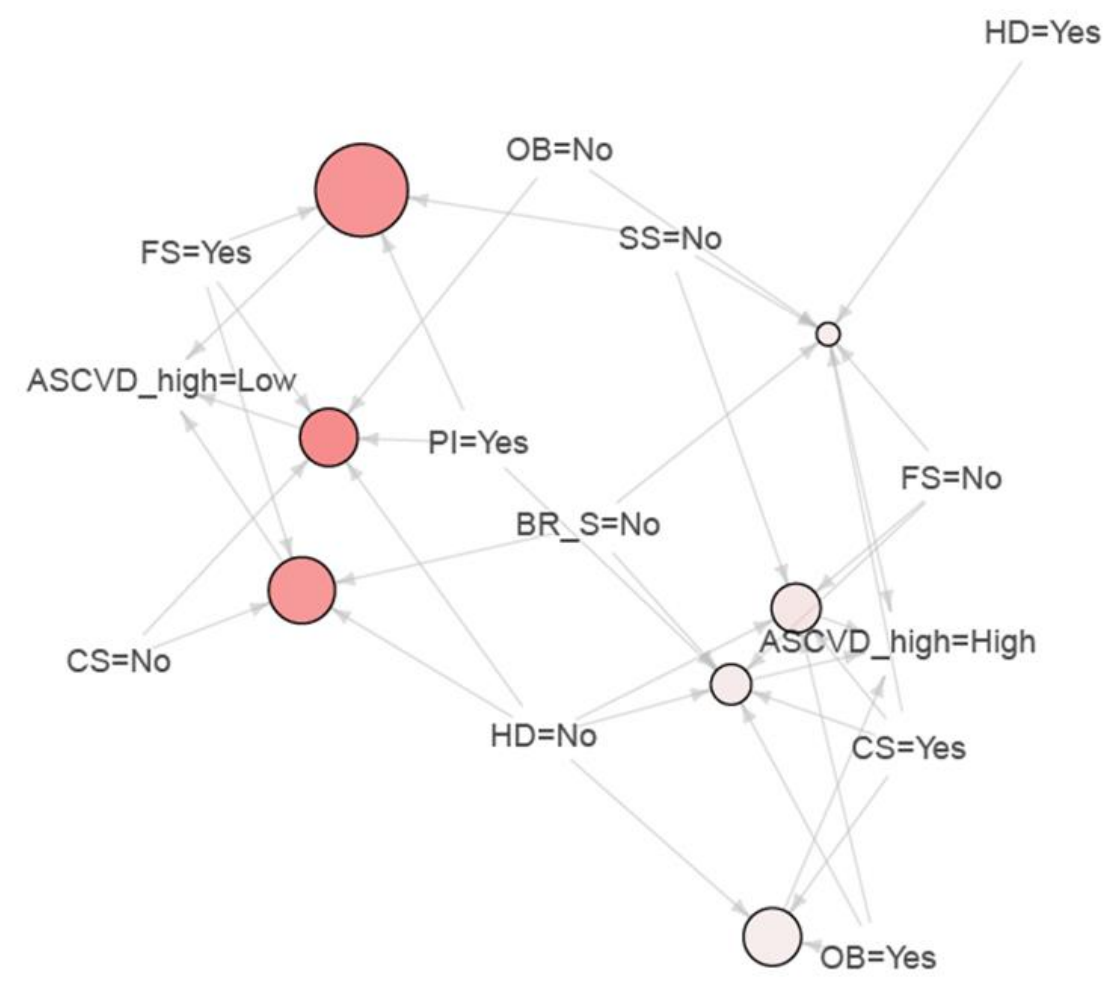

Figure 1. Association plot for male cancer survivors. Footnote: CS, current smoking; HD, heavy drinking; PI, physical inactivity; OB, obesity; SS, Suboptimal sleep; BR_S, breakfast skipping; FS, frequent snacking; ASCVD, atherosclerotic cardiovascular disease.

Table 4. Results of a priori algorithms of for ASCVD score in female cancer survivors.

\begin{tabular}{|c|c|c|c|c|c|c|}
\hline & LHS & RHS & Support & Confidence & Lift & Count \\
\hline 1 & $\{\mathrm{SS}=\mathrm{No}, \mathrm{FS}=\mathrm{Yes}\}$ & $\{$ ASCVD_high $=$ Low $\}$ & 0.052 & 1.000 & 1.324 & 28 \\
\hline 2 & $\{\mathrm{PI}=$ Yes, $\mathrm{FS}=$ Yes $\}$ & $\{$ ASCVD_high $=$ Low $\}$ & 0.054 & 1.000 & 1.324 & 29 \\
\hline 3 & $\{\mathrm{HD}=\mathrm{No}, \mathrm{FS}=\mathrm{Yes}\}$ & $\{$ ASCVD_high $=$ Low $\}$ & 0.061 & 1.000 & 1.324 & 33 \\
\hline 4 & $\{\mathrm{CS}=\mathrm{No}, \mathrm{FS}=\mathrm{Yes}\}$ & $\{$ ASCVD_high $=$ Low $\}$ & 0.058 & 1.000 & 1.324 & 31 \\
\hline 5 & $\{C S=$ No, PI $=$ No $\}$ & $\{$ ASCVD_high $=$ Low $\}$ & 0.069 & 0.902 & 1.195 & 37 \\
\hline 6 & $\{\mathrm{HD}=\mathrm{No}, \mathrm{PI}=\mathrm{No}, \mathrm{SS}=\mathrm{No}\}$ & $\{$ ASCVD_high $=$ Low $\}$ & 0.067 & 0.900 & 1.192 & 36 \\
\hline 7 & $\{C S=N o, P I=N o, S S=N o\}$ & $\{$ ASCVD_high $=$ Low $\}$ & 0.067 & 0.900 & 1.192 & 36 \\
\hline 8 & $\{C S=$ No, PI $=$ No, FS $=$ No $\}$ & $\{$ ASCVD_high $=$ Low $\}$ & 0.061 & 0.892 & 1.181 & 33 \\
\hline 9 & $\{C S=\mathrm{No}, \mathrm{HD}=\mathrm{No}, \mathrm{PI}=\mathrm{No}, \mathrm{SS}=\mathrm{No}, \mathrm{FS}=\mathrm{No}\}$ & $\{$ ASCVD_high $=$ Low $\}$ & 0.061 & 0.892 & 1.181 & 33 \\
\hline 10 & $\{\mathrm{PI}=\mathrm{No}, \mathrm{SS}=\mathrm{No}, \mathrm{BS}=\mathrm{Yes}, \mathrm{FS}=\mathrm{No}\}$ & $\{$ ASCVD_high $=$ Low $\}$ & 0.058 & 0.886 & 1.173 & 31 \\
\hline 11 & $\{\mathrm{HD}=\mathrm{No}, \mathrm{OB}=\mathrm{No}, \mathrm{BS}=\mathrm{Yes}\}$ & $\{$ ASCVD_high $=$ Low $\}$ & 0.135 & 0.820 & 1.086 & 73 \\
\hline 12 & $\{\mathrm{CS}=\mathrm{No}, \mathrm{OB}=\mathrm{No}, \mathrm{SS}=\mathrm{No}, \mathrm{BS}=\mathrm{No}\}$ & $\{$ ASCVD_high $=$ Low $\}$ & 0.332 & 0.803 & 1.063 & 179 \\
\hline
\end{tabular}

Abbreviation: LHS = left hand side, RHS = right hand side, CS=Current smoking, HD=Heavy drinking, PI=Physical inactivity, OB=Obesity, SS=Suboptimal sleep, BR_S=Breakfast skipping, FS=Frequent snacking. 
Graph for 12 rules

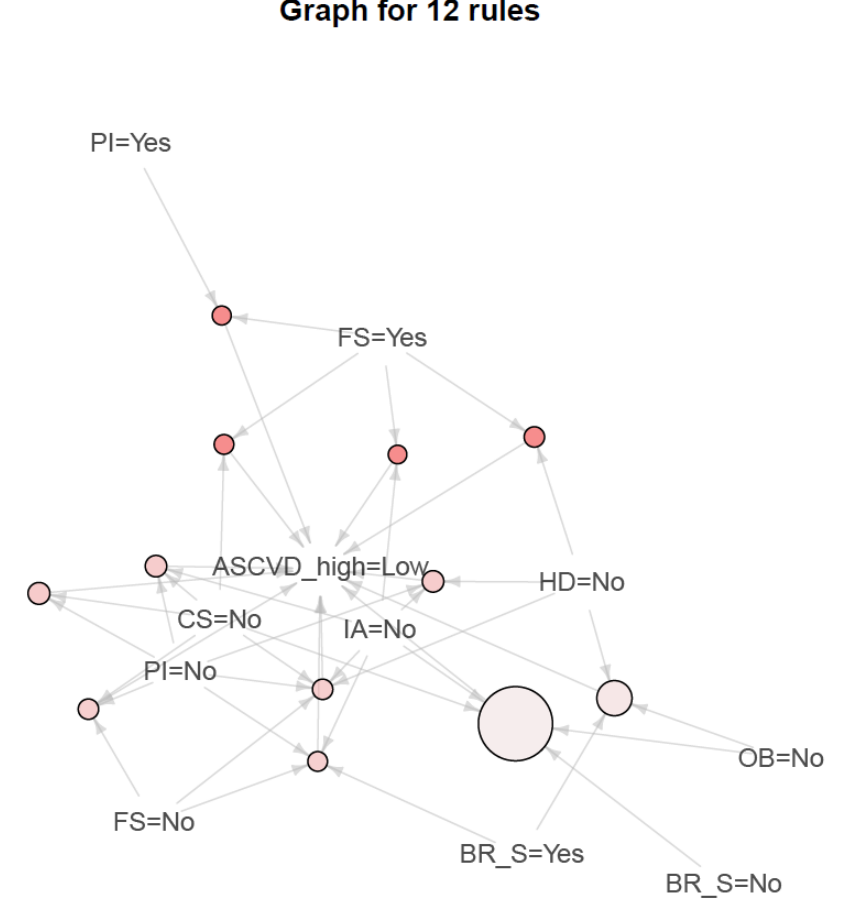

size: support $(0.052-0.332)$ color: lift $(1.063-1.324)$

Figure 2. Association plot for female cancer survivors. CS, current smoking; HD, heavy drinking; PI, physical inactivity; OB, obesity; IS, inadequate sleep; BR_S, breakfast skipping; FS, frequent snacking; ASCVD, atherosclerotic cardiovascular disease.

\section{Discussion}

In this study, we assessed the lifestyle risk behaviors that predict high ASCVD risk with logistic regression and identified some patterns of clustering of lifestyle risk behaviors in cancer survivors with high ASCVD risk. Current smoking and obesity were significant predictors for high ASCVD risk. Moreover, current smoking was the important behavior that influenced high ASCVD risk in male survivors within the ARM analysis, and it co-occurred with low physical activity, obesity and heavy drinking, simultaneously. Identifying important high risk clusters using ARM analysis is a useful method that can show the inter-correlation of several risk factors with small but significant associations in the same hierarchy.

According to the American Cancer Society and American Heart Association, the major modifiable factors affecting both cardiovascular disease and cancer are weight management, regular physical activity, healthy eating, drinking restrictions, and smoking, which are recommended to maintain a healthy lifestyle [29]. However, several reports on lifestyle behaviors in cancer survivors have reported that a large proportion of cancer survivors continued to smoke after the cancer diagnosis [30,31], were overweight or obese, and were significantly less likely to be physically active compared to the participants without a history of cancer diagnosis [30-32]. Our study also showed that a larger proportion of cancer survivors did not stop smoking, were physically inactive and obese, and had improper eating habits including skipping breakfast. In addition, $42 \%$ of cancer survivors had a $10 \%$ or higher risk of developing cardiovascular disease within 10-years. These findings reconfirm that lifestyle modification interventions such as smoking cessation are highly warranted in order to achieve optimal health outcomes among cancer patients.

In our binary logistic regression analysis results, smoking and obesity were significant predictors for high ASCVD risk in our cancer survivors. In our gender-specific ARM analyses, there was no significant association rules that related to the high ASCVD risk in female survivors. However, some patterns of co-existing multiple health risks associated with smoking have been observed in men with high risk of ASCVD. Smoking is one of the main causes of cancer, is associated with about $16 \%$ of all cancer development and $30 \%$ of 
all cancer deaths $[33,34]$. Furthermore, if smoking continues after cancer diagnosis, both all-cause mobility and cancer-specific mobility increase and are associated with increased risk of secondary cancer and complications associated with surgery, radiation therapy and chemotherapy $[35,36]$. From the point of view of atherosclerosis development, smoking is one of the most important preventable risks ever known. However, previous survey results showed that only $62 \%$ of patients who were smokers at the time of cancer diagnosis were instructed by doctors to quit smoking, and only $44 \%$ reported that health care providers had been trained on the dangers of smoking [37]. Therefore, our findings suggest that interventions are needed to systematically provide cancer patients with evidence-based interventions to help them to quit smoking and to address other high-risk health behaviors that contribute to cardiovascular disease risk.

In our study, physical inactivity was shown to be protective in our logistic regression analysis. However, aerobic exercise is associated with reducing chemotherapy-induced cardiotoxicity [38] and reducing the incidence of heart failure and coronary artery disease [39]. Therefore, the results of the preventive effect of physical inactivity on the ASCVD risk in our data should be evaluated cautiously, within the context the results of the logistic regression and the ARM analysis. In our subjects, the prevalence of physical inactivity was $93.1 \%$, and was the most frequent risk behavior observed in almost all cancer survivors. However, there was a significant clustering pattern observed among female cancer survivors who were physically inactive but not obese, did not smoke, abstained from alcohol, and who frequently snacked in the ARM analysis. These important association rules demonstrated that physical inactivity co-occurred alongside relatively healthy behaviors, which in turn seems to have a preventive effect in logistic regression analysis [40]. Therefore, we demonstrated in our study that implementing ARM with a logistic regression analysis can aid in interpretation of the association among several risk factors in a hierarchy that frequently co-occur within the same subject.

The ARM analysis was firstly introduced to identify specific purchasing patterns of consumers in the market [26], and this is commonly known as a market basket analysis. The ARM has been shown to be useful for identifying unique and important features among a non-hierarchical data set. This analytic technique is also used in the non-economic data mining field [41,42]. We transformed all lifestyle risk behaviors into dichotomous variables for ARM analysis. As ARM was developed to be used with Boolean data, use of this method is restricted to studies that are designed to analyze associations between binary variables [43]. In addition, we identified health related behaviors in left-hand side (antecedent) and the ASCVD group in right-hand side (consequent) in our ARM analysis, which suggests that health related risks were the cause. However, ARM analysis is not designed to evaluate causal relationships, but to show coincidental associations, which requires additional attention in its application and interpretation [44].

Our study had some limitations. First, our results should be interpreted with caution, as this study was not a cohort study that directly compared the occurrence of cardiovascular disease. Instead, our study was an observational case-control study using the 10-year ASCVD score, which is a surrogate marker for cardiovascular disease. Second, this study analyzed the lifestyles risk factors among cancer survivors based on the KNHANES survey, which may not represent all cancer survivors because it is likely that cancer survivors with less severe cancers responded more commonly than those with more severe cancers. Nevertheless, our work included data on cancer survivors extracted from the nationally representative population, minimizing the selection bias resulting from a retrospective study design. Lastly, we did not assess the dietary habit of our participants. As a result, there may be a residual confounding bias between lifestyle risk behavior and cardiovascular disease risk. Actually, dietary habit is the potent lifestyle risk behavior for cancer and cardiovascular disease $[45,46]$. In addition, it has been confirmed in a large number of prospective cohorts that the detailed assessment of dietary habit such as plant-based dietary pattern is beneficial to differentiate high or low cardiovascular disease risk in the general population $[47,48]$. However, for the ARM method we used, it is difficult to interpret 
and could be sensitive to local association rules if we put many variables into the model. Therefore, we could not include a variety of variables in this analytical model, such as diet habit. Further research is needed on whether health risk behavior, which reflects the concurrent diet status, is associate with the ASCVD risk.

In summary, current smoking and obesity were identified as important lifestyle risk behaviors in overall cancer survivors. In addition, multiple lifestyle risk behaviors cooccurred with smoking in male cancer survivors. Health care providers should consider that targeted education and interventions to address lifestyle risk behaviors should prioritize their patients who have these selective risk clusters for behavioral intervention.

Author Contributions: Conceptualization, K.B.C. and S.J.L.; Data curation, S.J.L.; Formal analysis, S.J.L.; Methodology, S.J.L.; Project administration, K.B.C. and S.J.L.; Supervision, K.B.C.; Writingoriginal draft, K.B.C. and S.J.L.; Writing-review and editing, K.B.C. and S.J.L. All authors have read and agreed to the published version of the manuscript.

Funding: This research was supported by Hallym University Research Fund (HRF-202005-008).

Institutional Review Board Statement: The study was conducted according to the guidelines of the Declaration of Helsinki and obtain an exemption approval by the Institutional Review Board of Hallym University (IRB No. 2020-05-05; Date of Approval: 18 May 2020).

Informed Consent Statement: Not applicable because open data were used in this study.

Data Availability Statement: Publicly available datasets were analyzed in this study. The data can be found here: http:/ / knhanes.cdc.go.kr; (Accessed date: 7 September 2020).

Acknowledgments: The authors would like to acknowledge the Korean Disease Control and Prevention Agency for access to the secondary data that was used to carry out this research. This research was supported by Hallym University Research Fund (HRF-202005-008).

Conflicts of Interest: The authors declare no conflict of interest.

\section{References}

1. National Cancer Information Center. Five Year Relative Survival Rate of Patients with Cancer in Korea 2017. Available online: https: / / www.cancer.go.kr (accessed on 30 December 2019).

2. Ning, Y.; Shen, Q.; Herrick, K.; Mikkelsen, R.; Anscher, M.; Houlihan, R.; Lapane, K. Abstract LB-339: Cause of Death in Cancer Survivors. In Proceedings of the AACR 103rd Annual Meeting 2012, Chicago, IL, USA, 31 March-4 April 2012 ; Volume 72 (Suppl. 8). Abstract nr LB-339. [CrossRef]

3. Mertens, A.C.; Liu, Q.; Neglia, J.P.; Wasilewski, K.; Leisenring, W.; Armstrong, G.T.; Robison, L.L.; Yasui, Y. Cause-specific late mortality among 5-year survivors of childhood cancer: The Childhood Cancer Survivor Study. J. Natl. Cancer Inst. 2008, 100, 1368-1379. [CrossRef] [PubMed]

4. Chao, C.; Xu, L.; Bhatia, S.; Cooper, R.; Brar, S.; Wong, F.L.; Armenian, S.H. Cardiovascular disease risk profiles in survivors of adolescent and young adult (AYA) cancer: The Kaiser Permanente AYA Cancer Survivors Study. J. Clin. Oncol. 2016, 34, 1626-1633. [CrossRef] [PubMed]

5. Bradshaw, P.T.; Stevens, J.; Khankari, N.; Teitelbaum, S.L.; Neugut, A.I.; Gammon, M.D. Cardiovascular disease mortality among breast cancer survivors. Epidemiol. (Camb. Mass.) 2016, 27, 6-13. [CrossRef] [PubMed]

6. Armenian, S.H.; Xu, L.; Ky, B.; Sun, C.; Farol, L.T.; Pal, S.K.; Douglas, P.S.; Bhatia, S.; Chao, C. Cardiovascular disease among survivors of adult-onset cancer: A community-based retrospective cohort study. J. Clin. Oncol. 2016, 34, 1122-1130. [CrossRef]

7. Fidler, M.M.; Reulen, R.C.; Henson, K.; Kelly, J.; Cutter, D.; Levitt, G.A.; Frobisher, C.; Winter, D.L.; Hawkins, M.M.; British Childhood Cancer Survivor Study (BCCSS) Steering Group. Population-based long-term cardiac-specific mortality among 34489 five-year survivors of childhood cancer in Great Britain. Circulation 2017, 135, 951-963. [CrossRef] [PubMed]

8. Bagnasco, F.; Caruso, S.; Andreano, A.; Valsecchi, M.G.; Jankovic, M.; Biondi, A.; Miligi, L.; Casella, C.; Terenziani, M.; Massimino, M.; et al. Late mortality and causes of death among 5-year survivors of childhood cancer diagnosed in the period 1960-1999 and registered in the Italian Off-Therapy Registry. Eur. J. Cancer 2019, 110, 86-97. [CrossRef]

9. Volkova, M.; Russell, R. Anthracycline cardiotoxicity: Prevalence, pathogenesis and treatment. Curr. Cardiol. Rev. 2011, 7, 214-220. [CrossRef]

10. Wadhwa, D.; Fallah-Rad, N.; Grenier, D.; Krahn, M.; Fang, T.; Ahmadie, R.; Walker, J.R.; Lister, D.; Arora, R.C.; Barac, I.; et al. Trastuzumab mediated cardiotoxicity in the setting of adjuvant chemotherapy for breast cancer: A retrospective study. Breast Cancer Res. Treat. 2009, 117, 357-364. [CrossRef] 
11. Hahn, E.; Jiang, H.; Ng, A.; Bashir, S.; Ahmed, S.; Tsang, R.; Sun, A.; Gospodarowicz, M.; Hodgson, D. Late cardiac toxicity after mediastinal radiation therapy for Hodgkin lymphoma: Contributions of coronary artery and whole heart dose-volume variables to risk prediction. Int. J. Radiat. Oncol. Biol. Phys. 2017, 98, 1116-1123. [CrossRef]

12. Giza, D.E.; Iliescu, G.; Hassan, S.; Marmagkiolis, K.; Iliescu, C. Cancer as a risk factor for cardiovascular disease. Curr. Oncol. Rep. 2017, 19, 39. [CrossRef]

13. Oeffinger, K.C.; Mertens, A.C.; Sklar, C.A.; Yasui, Y.; Fears, T.; Stovall, M.; Vik, T.A.; Inskip, P.D.; Robison, L.L.; Childhood Cancer Survivor Study. Obesity in adult survivors of childhood acute lymphoblastic leukemia: A report from the Childhood Cancer Survivor Study. J. Clin. Oncol. 2003, 21, 1359-1365. [CrossRef] [PubMed]

14. Lalonde, M.A. A New Perspective on the Health of Canadians: A Working Document; Government of Canada: Ottawa, ON, Canada, 1974.

15. Krokstad, S.; Ding, D.; Grunseit, A.C.; Sund, E.R.; Holmen, T.L.; Rangul, V.; Bauman, A. Multiple lifestyle behaviours and mortality, findings from a large population-based Norwegian cohort study-The HUNT Study. BMC Public Health 2017, 17, 58. [CrossRef]

16. Ezzati, M.; Vander Hoorn, S.; Rodgers, A.; Lopez, A.D.; Mathers, C.D.; Murray, C.J.; Comparative Risk Assessment Collaborating Group. Estimates of global and regional potential health gains from reducing muliple major risk factors. Lancet 2003, 362, 271-280. [CrossRef]

17. Zhao, G.; Li, C.; Okoro, C.A.; Li, J.; Wen, X.J.; White, A.; Balluz, L.S. Trends in modifiable lifestyle-related risk factors following diagnosis in breast cancer survivors. J. Cancer Surviv. 2013, 7, 563-569. [CrossRef] [PubMed]

18. Naik, H.; Qiu, X.; Brown, M.C.; Eng, L.; Pringle, D.; Mahler, M.; Hon, H.; Tiessen, K.; Thai, H.; Ho, V.; et al. Socioeconomic status and lifestyle behaviours in cancer survivors: Smoking and physical activity. Curr. Oncol. 2016, 23, e546-e555. [CrossRef] [PubMed]

19. Belloc, N.B. Relationship of health practices and mortality. Prev. Med. 1973, 2, 67-81. [CrossRef]

20. Kang, K.-W.; Sung, J.-H.; Kim, C.Y. High risk groups in health behavior defined by clustering of smoking, alcohol, and exercise habits: National Heath and Nutrition Examination Survey. J. Prev. Med. Public Health 2010, 43, 73-83. [CrossRef]

21. Ryu, S.Y.; Crespi, C.M.; Maxwell, A.E. Drinking patterns among Korean adults: Results of the 2009 Korean community health survey. J. Prev. Med. Public Health 2013, 46, 183-191. [CrossRef] [PubMed]

22. Haskell, W.L.; Lee, I.M.; Pate, R.R.; Powell, K.E.; Blair, S.N.; Franklin, B.A.; Macera, C.A.; Heath, G.W.; Thompson, P.D.; Bauman, A. Physical activity and public health: Updated recommendation for adults from the American College of Sports Medicine and the American Heart Association. Circulation 2007, 116, 1081-1093. [CrossRef]

23. Park, S.H.; Jang, S.Y.; Kim, H.; Lee, S.W. An association rule mining-based framework for understanding lifestyle risk behaviors. PLoS ONE 2014, 9, e88859. [CrossRef]

24. Buxton, O.M.; Marcelli, E. Short and long sleep are positively associated with obesity, diabetes, hypertension, and cardiovascular disease among adults in the United States. Soc. Sci. Med. 2010, 71, 1027-1036. [CrossRef]

25. Goff, D.C.; Lloyd-Jones, D.M.; Bennett, G.; Coady, S.; D'agostino, R.B.; Gibbons, R.; Greenland, P.; Lackland, D.T.; Levy, D.; O'Donnell, C.J.; et al. 2013 ACC/AHA guideline on the assessment of cardiovascular risk: A report of the American College of Cardiology/American Heart Association Task Force on Practice Guidelines. J. Am. Coll. Cardiol. 2014, 63, 2935-2959. [CrossRef] [PubMed]

26. Agrawal, R.; Imieliński, T.; Swami, A. Mining association rules between sets of items in large databases. In Proceedings of the 1993 ACM SIGMOD, International Conference on Management of Data; Association for Computing Machinery: Washington, DC, USA, 1993; Volume 22, pp. 207-216. [CrossRef]

27. Altaf, W.; Shahbaz, M.; Guergachi, A. Applications of association rule mining in health informatics: A survey. Artif. Intell. Rev. 2017, 47, 313-340. [CrossRef]

28. Harahap, M.; Husein, A.M.; Aisyah, S.; Lubis, F.R.; Wijaya, B.A. Mining association rule based on the diseases population for recommendation of medicine need. J. Phys. Conf. Ser. 2018, 1007, 012017. [CrossRef]

29. Eyre, H.; Kahn, R.; Robertson, R.M.; American Cancer Society; American Diabetes Association; American Heart Association; Clark, N.G.; Doyle, C.; Hong, Y.; Gansler, T.; et al. Preventing cancer, cardiovascular disease, and diabetes: A common agenda for the American Cancer Society, the American Diabetes Association, and the American Heart Association. Circulation 2004, 109, 3244-3255. [CrossRef]

30. Mayer, D.K.; Terrin, N.C.; Menon, U.; Kreps, G.L.; McCance, K.; Parsons, S.K.; Mooney, K.H. Health behaviors in cancer survivors. Oncol. Nurs. Forum 2007, 34, 643-651. [CrossRef] [PubMed]

31. Gallaway, M.S.; Glover-Kudon, R.; Momin, B.; Puckett, M.; Lunsford, N.B.; Ragan, K.R.; Rohan, E.A.; Babb, S. Smoking cessation attitudes and practices among cancer survivors-United States, 2015. J. Cancer Surviv. 2019, 13, 66-74. [CrossRef]

32. Hawkins, M.L.; Buys, S.S.; Gren, L.H.; Simonsen, S.E.; Kirchhoff, A.C.; Hashibe, M. Do cancer survivors develop healthier lifestyle behaviors than the cancer-free population in the PLCO study? J. Cancer Surviv. 2017, 11, 233-245. [CrossRef]

33. Jacobs, E.J.; Newton, C.C.; Carter, B.D.; Feskanich, D.; Freedman, N.D.; Prentice, R.L.; Flanders, W.D. What proportion of cancer deaths in the contemporary United States is attributable to cigarette smoking? Ann. Epidemiol. 2015, 25, 179-182. [CrossRef] [PubMed]

34. Andreotti, G.; Freedman, N.D.; Silverman, D.T.; Lerro, C.C.; Koutros, S.; Hartge, P.; Alavanja, M.C.; Sandler, D.P.; Freeman, L.B. Tobacco use and cancer risk in the Agricultural Health Study. Cancer Epidemiol. Biomark. Prev. 2017, 26, 769-778. [CrossRef] 
35. Yang, B.; Jacobs, E.J.; Gapstur, S.M.; Stevens, V.; Campbell, P.T. Active smoking and mortality among colorectal cancer survivors: The Cancer Prevention Study II nutrition cohort. J. Clin. Oncol. 2015, 33, 885-893. [CrossRef]

36. Messner, B.; Bernhard, D. Smoking and cardiovascular disease: Mechanisms of endothelial dysfunction and early atherogenesis. Arterioscler. Thromb. Vasc. Biol. 2014, 34, 509-515. [CrossRef]

37. Burke, L.; Miller, L.A.; Saad, A.; Abraham, J. Smoking behaviors among cancer survivors: An observational clinical study. J. Oncol. Pract. 2009, 5, 6-9. [CrossRef]

38. Marques-Aleixo, I.; Santos-Alves, E.; Mariani, D.; Rizo-Roca, D.; Padrão, A.I.; Rocha-Rodrigues, S.; Viscor, G.; Torrella, J.R.; Ferreira, R.; Oliveira, P.J.; et al. Physical exercise prior and during treatment reduces sub-chronic doxorubicin-induced mitochondrial toxicity and oxidative stress. Mitochondrion 2015, 20, 22-33. [CrossRef]

39. Jones, L.W.; Liu, Q.; Armstrong, G.T.; Ness, K.K.; Yasui, Y.; Devine, K.; Tonorezos, E.; Soares-Miranda, L.; Sklar, C.A.; Douglas, P.S.; et al. Exercise and risk of major cardiovascular events in adult survivors of childhood hodgkin lymphoma: A report from the childhood cancer survivor study. J. Clin. Oncol. 2014, 32, 3643-3650. [CrossRef]

40. Jhang, J.Y.; Tzeng, I.S.; Chou, H.H.; Jang, S.J.; Hsieh, C.A.; Ko, Y.L.; Huang, H.L. Association rule mining and prognostic stratification of 2-year longevity in octogenarians undergoing endovascular therapy for lower extremity arterial disease: Observational cohort study. J. Med. Internet Res. 2020, 22, e17487. [CrossRef] [PubMed]

41. Schäfer, I.; Kaduszkiewicz, H.; Wagner, H.O.; Schön, G.; Scherer, M.; van den Bussche, H. Reducing complexity: A visualisation of multimorbidity by combining disease clusters and triads. BMC Public Health 2014, 14, 1285. [CrossRef]

42. Li, Q.; Zhang, Y.; Kang, H.; Xin, Y.; Shi, C. Mining association rules between stroke risk factors based on the apriori algorithm. Technol. Health Care 2017, 25, 197-205. [CrossRef] [PubMed]

43. Kabir, M.M.J.; Xu, S.; Kang, B.H.; Zhao, Z. A new multiple seeds based genetic algorithm for discovering a set of interesting Boolean association rules. Expert Syst. Appl. 2017, 74, 55-69. [CrossRef]

44. Stilou, S.; Bamidis, P.D.; Maglaveras, N.; Pappas, C. Mining association rules from clinical databases: An intelligent diagnostic process in healthcare. Stud. Health Technol. Inform. 2001, 84, 1399-1403. [PubMed]

45. Key, T.J.; Allen, N.E.; Spencer, E.A.; Travis, R.C. The effect of diet on risk of cancer. Lancet 2002, 360, 861-868. [CrossRef]

46. Aune, D.; Giovannucci, E.; Boffetta, P.; Fadnes, L.T.; Keum, N.; Norat, T.; Greenwood, D.C.; Riboli, E.; Vatten, L.J.; Tonstad, S. Fruit and vegetable intake and the risk of cardiovascular disease, total cancer and all-cause mortality-a systematic review and dose-response meta-analysis of prospective studies. Int. J. Epdemiol. 2017, 46, 1029-1056. [CrossRef] [PubMed]

47. Satija, A.; Bhupathiraju, S.N.; Spiegelman, D.; Chiuve, S.E.; Manson, J.E.; Willett, W.; Rexrode, K.M.; Rimm, E.B.; Hu, F.B. Healthful and Unhealthful Plant-Based Diets and the Risk of Coronary Heart Disease in U.S. Adults. J. Am. Coll. Cardiol. 2017, 70, 411-422. [CrossRef] [PubMed]

48. Satija, A.; Bhupathiraju, S.N.; Rimm, E.B.; Spiegelman, D.; Chiuve, S.E.; Borgi, L.; Willett, W.C.; Manson, J.E.; Sun, Q.; Hu, F.B. Plant-Based Dietary Patterns and Incidence of Type 2 Diabetes in US Men and Women: Results from Three Prospective Cohort Studies. PLoS Med. 2016, 13, e1002039. [CrossRef] 